\title{
Curva Característica de Secagem da Madeira de Tectona grandis e Acacia mangium ao Ar Livre
}

\author{
Rafael Leite Braz ${ }^{1}$, Ana Paula Coelho Duarte ${ }^{2}$, José Tarcísio da Silva Oliveira ${ }^{3}$, \\ Javan Pereira Motta ${ }^{4}$, Antônio Marcos Rosado ${ }^{5}$
}
${ }^{1}$ Programa de Pós Graduação em Engenharia Florestal, Universidade Federal do Paraná - UFPR, Curitiba/PR, Brasil
${ }^{2}$ Programa de Pós Graduação em Ciências Florestais, Universidade Federal do Espírito Santo - UFES, Jerônimo Monteiro/ES, Brasil
${ }^{3}$ Departamento de Ciências Florestais e da Madeira, Universidade Federal do Espírito Santo - UFES, Jerônimo Monteiro/ES, Brasil
${ }^{4}$ Programa de Pós Graduação em Ciência e Tecnologia da Madeira, Universidade Federal de Lavras - UFLA, Lavras/MG, Brasil
${ }^{5}$ Bahia Specialty Cellulose/Copener, Alagoinhas, BA, Brasil

\section{RESUMO}

A secagem natural é uma alternativa que pode ser empregada como pré-secagem ou secagem definitiva para diversas madeiras com baixo custo e condições simples de trabalho. O presente trabalho foi realizado com o objetivo de estudar o comportamento das curvas características de secagem ao ar livre de tábuas de Acacia mangium e Tectona grandis. Árvores de cada espécie com idade de 15 anos foram abatidas, com toras de aproximadamente $3 \mathrm{~m}$. Essas foram desdobradas utilizando-se o sistema de cortes tangenciais para a obtenção das tábuas de $3,0 \mathrm{~cm}$ de espessura. Instalada a pilha de madeira para a secagem, a umidade inicial das amostras foi determinada e o acompanhamento foi realizado por meio de pesagens periódicas das amostras de controle. Observou-se que nas condições ambientais expostas, a madeira de Acacia mangium secou mais lentamente ao ar livre que a madeira de Tectona grandis. Recomenda-se a análise da curva de secagem para cada espécie separadamente.

Palavras-chave: secagem natural, umidade, pilha de madeira.

\section{Characteristic Air Drying Curve for Tectona grandis and Acacia mangium Lumber}

\begin{abstract}
Air drying is a simple, low-cost alternative that can be used in the pre-drying or definitive drying of several woods. The objective of the present work was to study the behavior of the characteristic air drying curve for Acacia mangium and Tectona grandis lumber. Fifteen-year-old trees of each species were cut into logs of approximately $3 \mathrm{~m}$ in length. The logs were sawn using a tangential cut system to obtain $3 \mathrm{~cm}$-thick boards. After the wood pile was mounted for drying, the moisture content of samples was determined, and monitoring occurred through the periodic weighing of the control samples. It was possible to observe that, under the environmental conditions imposed, Acacia mangium boards dried more slowly than Tectona grandis boards. A separate analysis of the drying curve for each species is recommended.
\end{abstract}

Keywords: natural drying, moisture content, lumber pile. 


\section{INTRODUÇÃO}

A madeira é um material biológico bastante heterogêneo, anisotrópico e higroscópico. A heterogeneidade referida se deve à diversidade de componentes que formam os tecidos que desempenham funções particulares a cada um, os quais por sua vez formam indivíduos complexos e com propriedades e características próprias.

A anisotropia se deve à composição dos elementos e suas disposições na formação do lenho, formando três planos - tangencial, radial e longitudinal - e cada plano reage de forma diferente tanto a cargas aplicadas quanto a secagem, podendo assim gerar defeitos nas peças. A mudança nas dimensões das peças de madeira em decorrência da variação no teor de umidade é de grande importância na secagem, a qual tem um efeito direto na utilização final do produto (Boutelje, 1962 apud Usta \& Guray, 2000).

Já a higroscopicidade é a capacidade de o material trocar umidade com o meio no qual está inserido, ou seja, em ambientes mais úmidos, o material ganhará umidade e em ambientes mais secos perderá umidade.

Essas características auxiliam o entendimento do processo da secagem na madeira e a ocorrência de alguns problemas ou defeitos que podem ocorrer. Durante a secagem, o primeiro tipo de água a ser liberado para a atmosfera é a água livre, ocasionando perda de massa da madeira. Quando toda a água livre é retirada da madeira tem-se o denominado ponto de saturação das fibras (PSF), variando em média entre $28 \%$ a $30 \%$ de umidade. Pode-se dizer que o PSF é alcançado quando a parede celular está completamente saturada de água mas não existe água livre nos lumes das células (Skaar, 1988).

Abaixo do PSF, a madeira começa a sofrer variações dimensionais, contraindo-se ao perder água ou inchando ao ganhar umidade. Essas variações dimensionais ocorrem de forma diferente em cada plano (tangencial, radial e longitudinal) e têm como consequência os defeitos nas peças de madeira. Empenamentos, abaulamentos, colapsos, encanoamentos e arqueamentos são alguns desses defeitos que podem vir a ocorrer em peças de madeira. Esses defeitos podem ser reduzidos controlando-se o processo de secagem.

Segundo Silva et al. (1997), a secagem da madeira é a evaporação da umidade superficial, absorvida pela atmosfera local enquanto a umidade do interior movimenta-se para as camadas mais superficiais. Dessa forma, a madeira exposta ao ar irá secar de forma natural até atingir um equilíbrio com a umidade relativa do ar em que está inserida. Essa umidade é chamada de teor de equilíbrio higroscópico (TEH). O estudo desse comportamento higroscópico da madeira é importante para um bom aproveitamento dos recursos florestais na fabricação de produtos distintos, pois dessa forma, retrações, inchamentos e defeitos oriundos da secagem poderão ser evitados. O TEH para uma mesma espécie varia conforme a localização geográfica e são essas variações que condicionam a umidade final da madeira seca ao ar.

Segundo Severo (2000), a principal razão para a secagem da madeira é assegurar-se de que a madeira seja dimensionalmente tão estável quanto possível antes do uso em uma estrutura ou item manufaturado. A maneira mais prática e barata de secar madeira é àquela ao ar livre. Essa secagem é obtida pela exposição da madeira empilhada adequadamente ao ar livre, onde a umidade relativa do ar e a sua intensidade são os principais fatores que interferem na taxa de secagem (Ponce \& Watai, 1985). De acordo com Gatto (2002), a secagem natural ou ao ar livre consiste em empilhar a madeira em local ventilado e, preferencialmente, coberto, a fim de evitar a incidência direta dos raios solares e da chuva, fazendo-se o controle do teor de umidade em intervalos regulares até que ela atinja o valor desejado, geralmente, em razão do uso final a que a madeira se destina ou das condições climáticas da região.

O empilhamento pode ser feito de diversas maneiras, entre elas pode-se usar o método padrão de empilhamento, que consiste em colocar tábuas pré-selecionadas lado a lado formando camadas superpostas. Entre uma camada e outra colocam-se sarrafos ou tabiques, chamados também de separadores, que permitem a passagem do ar entre as tábuas e retiram a umidade da madeira (Martins, 1988).

De acordo com Viscarra (1998), a perda de água pela madeira ocorre de forma diferente dependendo de se o teor de umidade está acima ou abaixo do ponto de saturação das fibras (PSF). Acima desse ponto, a velocidade de secagem permanece constante, desde que a temperatura e umidade relativa do ar permaneçam estáveis. Abaixo do PSF, a água retida na madeira se move mais lentamente. Sendo assim, a perda de umidade 
no início do processo é bem mais rápida, como pode ser visto na Figura 1, onde está esquematizada uma curva típica de secagem da madeira ao ar livre. $\mathrm{Na}$ secagem ao ar livre, a madeira atinge a umidade de equilíbrio lenta e suavemente. O tempo de secagem varia em função das condições climáticas de cada região. Caso haja necessidade de umidade da madeira abaixo desse ponto, deve-se proceder à secagem em estufas (Mendes et al., 1996).

A curva típica de secagem é uma maneira prática e bem-sucedida de avaliar e controlar a secagem natural no local onde é montada uma pilha de secagem de peças de madeira. A partir de algumas amostras controla-se a massa sistematicamente até que ela atinja uma massa constante. Ao atingir essa massa, toda a pilha poderá ser considera seca ao ar livre.

Visando obter informações para otimizar o processo de secagem natural de madeira serrada, o presente trabalho teve como objetivo principal determinar a perda de umidade em função do tempo através da curva característica de secagem ao ar livre das madeiras de Tectona grandis e Acacia mangium.

\section{MATERIAL E MÉTODOS}

A pilha de secagem foi composta por madeira serrada das espécies de Tectona grandis L. f. (teca) e Acacia mangium Willd (acácia), fornecida pela empresa Celulose Nipo Brasileira (Cenibra SA). O material proveio de plantios experimentais, com 15 e 17 anos, respectivamente, teca e acácia, cultivado na região do Vale do Rio Doce, no estado de Minas Gerais. Cinco

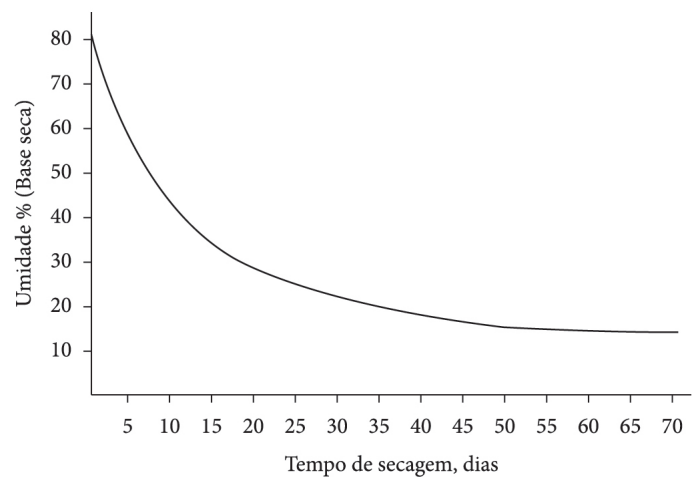

Figura 1. Curva típica de secagem da madeira ao ar livre. Fonte: Ponce \& Watai, 1985.

Figure 1. Tipical air drying curve of the wood. Source: Ponce \& Watai, 1985. árvores de cada espécie foram abatidas, com toras de aproximadamente $3 \mathrm{~m}$, sendo duas toras por árvore. O desdobro da madeira foi realizado por meio de uma serra de fita, na serraria localizada no município de Jerônimo Monteiro, no estado do Espírito Santo, sendo adotado o sistema de cortes tangenciais para a obtenção das tábuas com dimensões de $3 \times 300 \mathrm{~cm}$ (espessura $\times$ comprimento) e largura variável.

A montagem da pilha de secagem foi feita na área do Departamento de Ciências Florestais e da Madeira do Centro de Ciências Agrárias da Universidade Federal do Espírito Santo (UFES), no município de Jerônimo Monteiro, ES, a $120 \mathrm{~m}$ de altitude. Optou-se por um local plano, bem drenado e com boas condições de circulação de ar. Durante o período experimental, a temperatura na região variou de $19,25^{\circ} \mathrm{C}$ a 29,14 ${ }^{\circ} \mathrm{C}$, com umidade relativa entre $50,62 \%$ a $86,4 \%$ e precipitação de, no máximo, 79,8 mm.

A pilha de secagem ao ar livre (Figura 2) foi montada alternando tabiques separadores em posição perpendicular às tábuas. Sua base foi feita com moirões serrados de eucalipto tratado a $40 \mathrm{~cm}$ de altura do solo, espaçados a $60 \mathrm{~cm}$. O comprimento da pilha de secagem foi em função do comprimento total das tábuas, com $300 \mathrm{~cm}$, e a largura total, de $160 \mathrm{~cm}$. Os tabiques utilizados tinham seç̧ão transversal quadrada com $3 \mathrm{~cm}$ de lado e foram espaçados a $40 \mathrm{~cm}$ entre si. As tábuas foram desdobradas na serraria com espessura de aproximadamente $3 \mathrm{~cm}$. A altura total da pilha, ou seja, da cobertura até o chão, foi de $190 \mathrm{~cm}$, sendo a altura das tábuas e tabiques de $120 \mathrm{~cm}$.

A parte superior da pilha foi devidamente protegida contra chuva e insolação direta através de

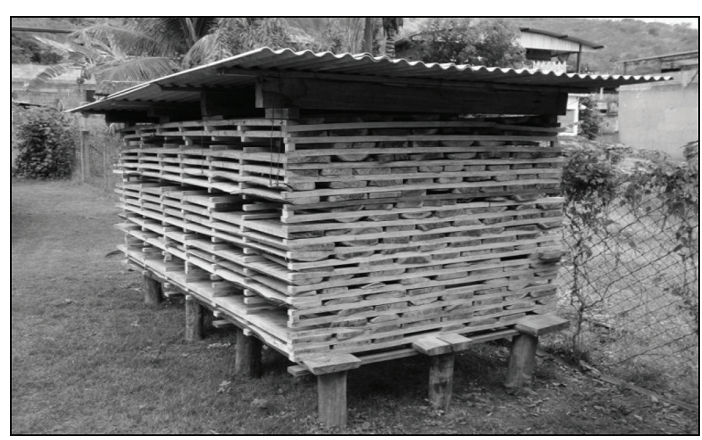

Figura 2. Pilha de secagem ao ar livre da madeira de Tectona grandis e Acacia mangium, em Jerônimo Monteiro, ES.

Figure 2. Air drying piles of Acacia mangium and Tectona grandis wood in Jerônimo Monteiro, ES. 
uma cobertura com telhas de fibrocimento, presa à pilha de forma a evitar que fossem arrancadas por eventuais ventos fortes. A cobertura tinha inclinação de aproximadamente $5 \%$, para permitir o escoamento de água de chuva, projeção de $40 \mathrm{~cm}$ na extremidade mais elevada, $35 \mathrm{~cm}$ na extremidade mais baixa e 30 $\mathrm{cm}$ em cada uma das laterais.

Foram retiradas das tábuas de cada espécie amostras que foram distribuídas na pilha para o controle de perda de umidade. A perda da massa foi acompanhada por pesagens periódicas das amostras até que apresentassem massa constante.
Em seguida, essas amostras foram levadas para estufa de laboratório e secas a $103 \pm 2{ }^{\circ} \mathrm{C}$. A partir dos dados da massa úmida e seca das amostras, calculouse a umidade do material ao longo do tempo, em seguida, as curvas características de secagem ao ar livre foram plotadas.

\section{RESULTADOS E DISCUSSÃO}

A Tabela 1 mostra os resultados da perda de massa de água das amostras, o teor de umidade e a taxa de secagem para a madeira de Tectona grandis e Acacia

Tabela 1. Variação da massa de água e da taxa de secagem em função do tempo de secagem para a madeira de Tectona grandis e Acacia mangium.

Table 1. Variation of the water content and the drying rate variation related to drying time for Tectona grandis and Acacia mangium wood.

\begin{tabular}{|c|c|c|c|c|c|c|c|}
\hline \multicolumn{8}{|c|}{ Tectona grandis } \\
\hline $\begin{array}{l}\text { Tempo } \\
\text { (dias) }\end{array}$ & $\begin{array}{c}\text { Massa de } \\
\text { água (g) }\end{array}$ & $\begin{array}{c}\text { Teor de } \\
\text { umidade } \\
(\%)\end{array}$ & $\begin{array}{l}\text { Taxa de } \\
\text { secagem } \\
\text { (g/dias) }\end{array}$ & $\begin{array}{c}\text { Tempo } \\
\text { (dias) }\end{array}$ & $\begin{array}{c}\text { Massa de } \\
\text { água (g) }\end{array}$ & $\begin{array}{c}\text { Teor de } \\
\text { umidade } \\
(\%)\end{array}$ & $\begin{array}{c}\text { Taxa de } \\
\text { secagem } \\
\text { (g/dias) }\end{array}$ \\
\hline 0 & 2485,8 & 70,9 & - & 47 & 1669,5 & 15,0 & $-0,05$ \\
\hline 5 & 2115,3 & 45,4 & 5,11 & 50 & 1666,3 & 14,9 & 0,06 \\
\hline 8 & 2018,0 & 38,6 & 2,26 & 54 & 1649,5 & 13,8 & 0,28 \\
\hline 12 & 1917,5 & 31,6 & 1,74 & 57 & 1669,5 & 15,2 & $-0,49$ \\
\hline 15 & 1870,0 & 28,4 & 1,08 & 61 & 1655,3 & 14,2 & 0,26 \\
\hline 19 & 1823,8 & 25,3 & 0,78 & 64 & 1637,8 & 13,0 & 0,40 \\
\hline 22 & 1803,5 & 23,9 & 0,45 & 68 & 1631,8 & 12,6 & 0,10 \\
\hline 26 & 1749,3 & 20,2 & 0,93 & 71 & 1629,3 & 12,5 & 0,05 \\
\hline 29 & 1740,8 & 19,6 & 0,18 & 75 & 1622,0 & 12,0 & 0,12 \\
\hline 33 & 1718,8 & 18,2 & 0,36 & 78 & 1611,5 & 11,2 & 0,24 \\
\hline 36 & 1705,8 & 17,4 & 0,27 & 82 & 1598,0 & 10,3 & 0,23 \\
\hline 40 & 1688,5 & 16,2 & 0,28 & 85 & 1597,5 & 10,3 & 0,01 \\
\hline 43 & 1667,5 & 14,8 & 0,47 & 89 & 1612,8 & 11,4 & $-0,27$ \\
\hline \multicolumn{8}{|c|}{ Acacia mangium } \\
\hline $\begin{array}{l}\text { Tempo } \\
\text { (dias) }\end{array}$ & $\begin{array}{c}\text { Massa de } \\
\text { água (g) }\end{array}$ & $\begin{array}{c}\text { Teor de } \\
\text { umidade } \\
(\%)\end{array}$ & $\begin{array}{c}\text { Taxa de } \\
\text { secagem (g/ } \\
\text { dias) }\end{array}$ & $\begin{array}{c}\text { Tempo } \\
\text { (dias) }\end{array}$ & $\begin{array}{l}\text { Massa de } \\
\text { água (g) }\end{array}$ & $\begin{array}{c}\text { Teor de } \\
\text { umidade } \\
(\%)\end{array}$ & $\begin{array}{c}\text { Taxa de } \\
\text { secagem } \\
\text { (g/dias) }\end{array}$ \\
\hline 0 & 2573,5 & 96,5 & - & 54 & 1786,5 & 36,4 & 0,59 \\
\hline 5 & 2337,5 & 78,5 & 3,60 & 57 & 1789,0 & 36,6 & $-0,06$ \\
\hline 8 & 2257,5 & 72,3 & 2,04 & 61 & 1769,5 & 35,1 & 0,37 \\
\hline 12 & 2171,0 & 65,7 & 1,65 & 64 & 1742,5 & 33,0 & 0,69 \\
\hline 15 & 2123,5 & 62,1 & 1,21 & 68 & 1717,5 & 31,1 & 0,48 \\
\hline 19 & 2071,0 & 58,1 & 1,00 & 71 & 1703,0 & 30,0 & 0,37 \\
\hline 22 & 2045,5 & 56,2 & 0,65 & 75 & 1683,5 & 28,5 & 0,37 \\
\hline 26 & 1987,0 & 51,7 & 1,12 & 78 & 1660,0 & 26,7 & 0,60 \\
\hline 29 & 1970,0 & 50,4 & 0,43 & 82 & 1631,5 & 24,5 & 0,54 \\
\hline 33 & 1934,5 & 47,7 & 0,68 & 85 & 1622,0 & 23,8 & 0,24 \\
\hline 36 & 1910,0 & 45,8 & 0,62 & 89 & 1619,5 & 23,6 & 0,05 \\
\hline 40 & 1881,0 & 43,6 & 0,55 & 92 & 1607,5 & 22,7 & 0,30 \\
\hline 43 & 1848,5 & 41,1 & 0,83 & 97 & 1604,5 & 22,5 & 0,05 \\
\hline 47 & 1830,5 & 39,7 & 0,34 & 102 & 1590,0 & 21,4 & 0,22 \\
\hline 50 & 1817,5 & 38,7 & 0,33 & & & & \\
\hline
\end{tabular}


mangium. Tanto para a madeira de teca quanto para a de acácia, os valores mostraram o comportamento característico da madeira: as maiores taxas de secagem ocorreram nas primeiras semanas de secagem e, à medida que o teor de umidade foi-se reduzindo, a taxa de secagem decresceu com o tempo.

A madeira de teca foi empilhada com teor de umidade inicial de $71 \%$, em média, e a de acácia apresentou-se um pouco mais úmida, com $96,5 \%$ de teor de umidade, sendo os valores máximos de umidade de $77,6 \%$ e $100,9 \%$ para teca e acácia, respectivamente. Nota-se o comportamento bem típico de secagem das madeiras, porém na secagem da madeira de teca houve uma perda de umidade mais acelerada nos cinco primeiros dias, de cerca de $25,5 \%$, sendo a perda de umidade da madeira de acácia nos cinco primeiros dias de $18 \%$. Verifica-se também que entre 54 e 57 dias de secagem houve um aumento no teor de umidade em ambas as espécies, o que coincide com um período de chuvas no local. Logo após esse período, a pilha de madeira voltou a perder umidade normalmente.

A perda de massa de água da madeira de acácia estabilizou-se a $21,4 \%$ de umidade, acima da média da teca, de $11,4 \%$. A taxa de secagem da teca foi mais acelerada no começo e sua umidade inicial foi menor que da acácia. Pode-se afirmar que a madeira de acácia deveria ter tido a sua massa controlada por mais alguns dias, principalmente se lembrarmos que a pilha foi montada no início de setembro e as medições terminaram em dezembro, ou seja, houve um período de chuva considerável nesse meio tempo. Klitzke (2003) e Stein (2003) explicam que o umedecimento da madeira ocorre, pois as chuvas, geralmente, são acompanhadas de alta umidade relativa do ar e a magnitude desse umedecimento dependerá da duração e da intensidade da chuva e da velocidade dos ventos após a sua ocorrência.

Na Figura 3 observa-se mais claramente a diferença entre as curvas de secagem da madeira de teca e da de acácia.

Nota-se que a inclinação inicial da curva é maior para a madeira de teca, indicando uma maior taxa inicial de secagem. Ao final da curva nota-se que a madeira de teca estabilizou-se próximo a $12 \%$ com tempo menor, pois com a mesma quantidade de dias de secagem (89 dias), a madeira de acácia ainda se encontrava com $23,6 \%$ de umidade, em média.

Silva et al. (1997) encontraram umidade final média de até $18,42 \%$ de umidade para tábuas de Eucalyptus grandis com aproximadamente $3 \mathrm{~cm}$ de espessura, secas ao ar livre em Ubá, MG, porém de acordo com os dados expostos no mesmo trabalho, a umidade de equilíbrio da madeira poderia chegar até um máximo de $23,05 \%$, em dias mais quentes e chuvosos.

Jankowsky et al. (2010), estudando a influência da resinagem na secagem e qualidade em madeiras do gênero Pinus, encontrou umidade de equilíbrio da madeira variando de $11,0 \%$ a $12,6 \%$ para o Pinus hondurensis e $10,7 \%$ a $11,7 \%$ para o Pinus elliottii e concluiu ainda que para a secagem ao ar livre satisfatória dessas espécies é esperado um período de 70 dias e de 90 dias de secagem, respectivamente. No presente trabalho, a madeira de teca chegou à umidade de equilíbrio esperada com aproximadamente 89 dias, porém a madeira de acácia com 102 dias ainda se encontrava com um teor de umidade de $21,4 \%$.

Na Figura 4 estão ilustradas as taxas de secagem em função do teor de umidade para as duas espécies.

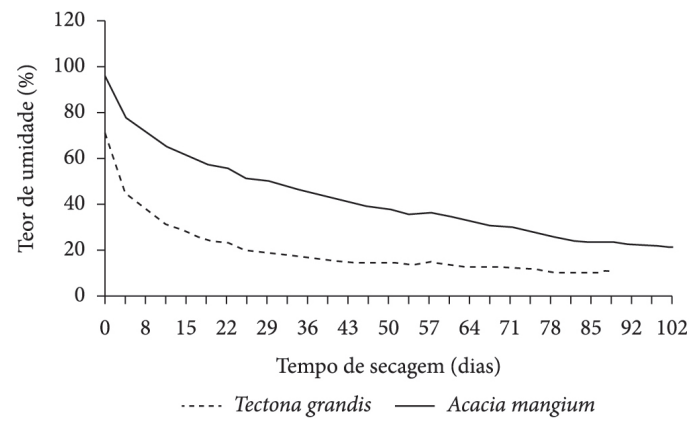

Figura 3. Curvas de secagem ao ar livre para a madeira de Tectona grandis e Acacia mangium.

Figure 3. Air drying curves of Tectona grandis and Acacia mangium wood.

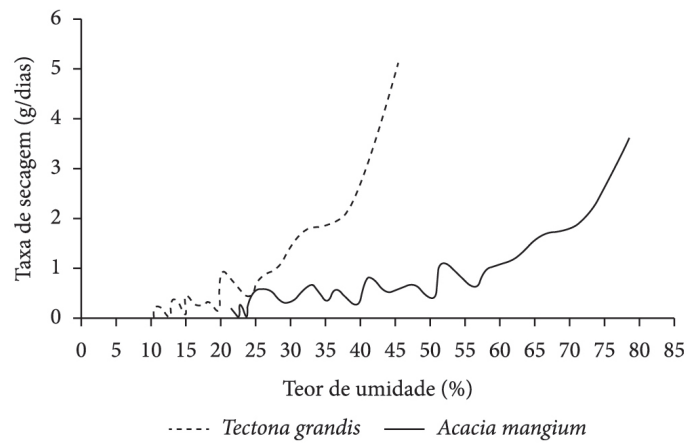

Figura 4. Gráfico da taxa de secagem em função do teor de umidade para a madeira de Tectona grandis e de Acacia mangium.

Figure 4. Graphic of drying rate as a function of moisture content for Tectona grandis and Acacia mangium wood. 
Observa-se que, na fase inicial, a taxa de secagem para as duas espécies apresenta alta queda, resultado da movimentação da água livre presente na madeira sem impedimento. Isso se justifica pelo fato de que, ao iniciar-se a secagem, a água livre presente nas cavidades celulares dos elementos vasculares da madeira sai facilmente através da evaporação, uma vez que é mantida na madeira por forças capilares muito fracas, perdendo-se facilmente todo esse tipo de água.

A taxa de secagem para a madeira de teca possui uma alta queda até aproximar-se dos $35 \%$ de umidade, depois apresenta uma fase estável, até uma umidade próxima ao ponto de saturação das fibras, voltando a cair em seguida. Para a madeira de acácia, a tendência da taxa de secagem não é muito clara, com aumentos e diminuições após a queda da taxa até aproximadamente $60 \%$ de umidade. Segundo Santini (1992), a taxa de secagem é influenciada por uma série de fatores relacionados com a própria madeira, com a pilha e sua distribuição no pátio e com as condições climáticas.

A massa específica é uma variável de muita importância na taxa de secagem, pois normalmente quanto maior a massa específica menor a permeabilidade da madeira e mais lenta deverá ser a sua secagem, seja natural ou artificial. No entanto, ocorrem exceções ocasionadas por características de permeabilidade, como a presença de algumas substâncias no interior da célula (Klitzke, 2003). Essa exceção pôde ser observada no presente trabalho, uma vez que a madeira Tectona grandis apresenta uma massa específica básica de 0,54 $\mathrm{g} / \mathrm{cm}^{3}$, segundo Motta (2011), superior à da madeira de Acacia mangium, cuja densidade básica é de 0,46 $\mathrm{g} / \mathrm{cm}^{3}$, de acordo com Paterlini (2011). Conforme descrito por Duarte et al. (2010), a madeira de acácia apresenta uma maior concentração de goma no seu interior, o que pode ter influenciado no processo de secagem da madeira, fazendo com que a velocidade da perda de umidade para a madeira de teca seja superior à da acácia

As variações de umidade durante o período de secagem da madeira podem também ser reflexo da instabilidade do clima na época em que a pilha foi montada, intercalando-se, durante o período de secagem da madeira, períodos de chuva e frio com períodos de muito calor e sol em um curto espaço de tempo, além de as variações serem condicionadas pelas condições ambientais e pelas características anatômicas e físicas de cada espécie com relação à permeabilidade de seu material. Recomenda-se que a secagem da madeira ao ar livre ocorra na região em que a madeira for ser utilizada definitivamente, do contrário, antes da utilização definitiva o material deve passar por um período de aclimatização.

\section{CONCLUSÕES}

Com base nos resultados de secagem para as duas espécies, concluiu-se que:

A maior perda de umidade para as duas espécies ocorreu nas primeiras semanas de secagem;

A madeira de Acacia mangium secou mais lentamente ao ar livre do que a madeira de Tectona grandis, apesar de essa madeira apresentar menor densidade básica;

É importante conhecer as características de permeabilidade da madeira, a fim de que o ensaio de secagem seja interpretado da forma mais adequada possível, proporcionando uma base de dados de melhor qualidade para o processo de secagem das indústrias;

As condições ambientais na época do experimento, com períodos chuvas e sol em um curto espaço de tempo, influenciaram diretamente na secagem do material;

Dessa forma, pode-se confirmar a importância de analisarmos as curvas características de secagem para cada espécie separadamente, bem como suas características anatômicas, físicas e químicas, para proporcionar uma secagem ótima e eficiente e obter-se um produto final pronto para ser usado adequadamente e com mínimos defeitos.

\section{AGRADECIMENTOS}

À Celulose Nipo Brasileira SA (Cenibra), pela disponibilização do material e ao CNPq pela concessão de bolsa de produtividade em pesquisa a um dos autores.

\section{STATUS DA SUBMISSÃO}

Recebido: 5 abr., 2013

Aceito: 25 ago., 2014 


\section{AUTOR(ES) PARA CORRESPONDÊNCIA}

Rafael Leite Braz

Programa de Pós-graduação em Engenharia Florestal, Universidade Federal do Paraná UFPR, CEP 80210-300 Curitiba, PR, Paraná, Brasil.

e-mail: rafaellbraz@yahoo.com.br

\section{REFERÊNCIAS}

Duarte APC, Motta JP, Braz RL, Rodrigues BP, Mauri R, Oliveira JTS. Avaliação da densidade básica e anatomia da madeira de Acácia mangium proveniente de reflorestamento. In: Anais do XII Encontro Brasileiro em Madeiras e em Estruturas de Madeiras; 2010; Lavras, MG.

Gatto DA. Avaliação quantitativa e qualitativa da utilização madeireira na região da quarta colônia de imigração italiana do Rio Grande do Sul [dissertação]. Santa Maria: Universidade Federal de Santa Maria; 2002.

Jankowsky IP, Antonelli PO, Garcia JN. Influência da resinagem na secagem ao ar da madeira de Pinus elliottii e Pinus hondurensis. In: Anais do XII Encontro Brasileiro em Madeiras e em Estruturas de Madeiras; 2010; Lavras, MG.

Klitzke RJ. Secagem da madeira. Curitiba: UFPR; 2003.

Martins VA. Secagem da madeira serrada. Brasília: Gutenberg; 1988.

Mendes LM, Lima JT, Calegário N. Umidades de equilíbrio médias de madeiras para 206 cidades Brasileiras calculadas pela fórmula de Simpson. Madeira 1996; 26:18.
Motta JP. Propriedades tecnológicas da madeira de Tectona Grandis l.f. proveniente de Vale do Rio Doce, Minas Gerais [dissertação]. Jerônimo Monteiro: Universidade Federal do Espírito Santo; 2011.

Paterlini EM. Caracterização tecnológica da madeira de acácia (acacia mangium willd) para produtos sólidos [monografia]. Jerônimo Monteiro: Universidade Federal do Espírito Santo; 2011.

Ponce RH, Watai LT. Manual de secagem da Madeira. Brasília: STI/IPT; 1985.

Santini EJ. Métodos usuais de secagem da madeira. In: Anais do I Seminário Sobre Secagem da Madeira; 1992; Santa Maria. Centro de Pesquisas Florestais; 1992.

Severo ETD. Qualidade da secagem de madeira serrada de Eucalyptus dunnii. Ciência Florestal 2000; 10(1): 109-124.

Silva JRM, Mendes LM, Wenzel MK, Trugilho PF. Secagem ao ar livre da madeira de Eucalyptus grandis para a produção de móveis. Cerne 1997; 3(1): 170-186.

Skaar C. Wood-water relations. New York: Springer-Verlag; 1988.. http://dx.doi.org/10.1007/978-3-642-73683-4.

Stein FR. Avaliação técnica do tempo de estocagem da madeira. 2003. [cited 2003]. Available from: http:// www. celuloseonline.com.br/imagembank/Docs/Doc Bank/ Doutor\% 20Celulose/2003SteinFR.pdf.

Usta I, Guray A. Comparison of the swelling and shrinkage characteristics of Corsican Pine (Pinus nigra var. mantina). Turkish Journal of Agriculture and Forestry 2000; 24: 461-464.

Viscarra S. Guía para el secado de la madera em hornos. Bolivia: USAID; 1998. Documento Técnico 69. 